\title{
Antiulcerogenic activities of Agelanthus dodoneifolius leaf against acetyl salicylate and ethanol induced ulceration in rats
}

\author{
Mohammed Bala Alkali *, Jigam Ali Audu, Abubakar Abdulkadir, Abdulkadir Abdullahi and Audu \\ Mohammed
}

Department of Biochemistry, Federal University of Technology, Minna. Nigeria.

Publication history: Received on 21 August 2019; revised on 28 September 2019; accepted on 30 September 2019

Article DOI: https://doi.org/10.30574/gscbps.2019.9.1.0181

\begin{abstract}
Antiulcer and antioxidant activities of crude methanol (800 and $1600 \mathrm{mg} / \mathrm{kg} \mathrm{bw}$ ), n-hexane and ethyl acetate fractions (800 mg/kg bw) of Agelanthus dodoneifolius were investigated against acetylsalicylate and ethanol induced ulcer in rats. The methanol fraction had the highest ulcer protective effect $(73.33 \pm 7.40 \%)$, better than the cimetidine $(60.00 \pm 8.54$ $\%)$ while the ethyl acetate fraction had the least $(26.66 \pm 6.66 \%)$ in ethanol model, however, in acetyl salicylate model, crude extract exhibited the highest (54.16 $\pm 4.16 \%)$ and the lowest $(33.33 \pm 4.16 \%)$ protective effect at 1600 and 800 $\mathrm{mg} / \mathrm{kgbw}$ respectively. The methanol faction preserved the integrity of the epithelial mucosal better than the other fractions. Treatment with crude and fractions of $A$. dodenofolius significantly $(\mathrm{p}<0.05)$ increased the activities of SOD and Catalase and decreases the MDA concentration when compared with ulcerative untreated rats in both ulcer models. In conclusion, $A$. dodoneifolius could serve as a sources of new plant based antiulcer agent.
\end{abstract}

Keywords: Methanol extract; A. dodoneifolius; Acetyl salisylate induced; Ethanol induced; Ulcer protective activity

\section{Introduction}

Ulcer disease is a condition that affects the skin around the lining of human body either externally or around its internal viscera: typically characterized by the presence of an open sore in the lining of epithelial cells or deep lesion in the body [1]. Ulcer disease is seen as one of the world's most common illnesses, which is a global health problem affecting the youths [2]. The major aggressive factors that cause ulcer are pepsin, gastric acid, non-steroidal anti-inflammation drugs (NSAID), bile salts, abnormal motility, alcohol and a bacterial infection known as Helicobacter pylori. Although, there are ample factors that could be protective in function which safeguard the stomach from ulcer formation and these include among others; bicarbonate production, mucus secretion, gastro-protective prostaglandin synthesis and normal tissue microcirculation [3]. The proposed strategies put in place for the prevention of peptic ulcer disease are those of attenuating gastric acid production and increasing gastric mucosal protection [4]. Evaluation of therapeutic potential of medicinal plant against gastric ulcer is attested by employing the use of ethanol to induce gastric injury [5]. Ethanol elicit its effects by causing intense lesions in the sub-mucosa by penetrating through the membrane [6], elevating Reactive Oxygen Species (ROS) formation, and reduces the mucus membrane formation [7] which can cause death of cells around the gastric mucosa. Ethanol inhibits endogenous prostaglandins formation and also suppresses cyclooxygenase enzyme activitiues [8].

Herbal medicine has witnessed widespread attention globally in recent years because of their use in the field of medicine for treating many diseases. Loranthaceae also known as is a parasitic plant growing on a large number of tree species such as Parkia biglobosa, Tamarindus indica, acacia, kola, citrus, orange and many other trees as a host plants. Presence of tannins, flavonoids, alkaloids and saponins were revealed in the methanol and chloroform extracts of the plant [9]

\footnotetext{
${ }^{*}$ Corresponding author

E-mail address: b.mohammed@futminna.edu.ng
} 
Incidence of ulcer was discovered in about 87.4 million people worldwide in 2015 and about $10 \%$ of people develop peptic ulcer at some point in their life time. Peptic ulcer also accounted for the deaths of 267,500 people in 2015 alone [10]. It is known to be the most predominant of the gastrointestinal diseases with a global prevalence of around $4 \%$ of the population [11].

Liver toxicity also known as hepatotoxicity is a common disease resulting into serious debilities such as serious metabolic disorders to even death. Hepatotoxicity in often due to increase free radical. Free radicals produced by toxicant metabolism initiate what is termed toxicant cascade [12]. The free radical scavengers known to be endogenous in the body includes among others; catalase, super oxide dismutase, reduced glutathione, vitamin C and vitamin E, are present in the body. Cell necrosis is initiated by inhibited free radicals thus leading to hepatotoxicity [13]. Synthetic drugs have little to offer for alleviation of these disorders. Natural occurring antioxidants have better antioxidant activity from their natural source and this is why they are preferred to synthetic antioxidants [14]. The use of NSAIDs is crucial for the treatment of inflammatory diseases, it however presented some adverse effects such as gastric/ duodenal ulceration and renal failure which pose a serious threat in their medical use for treatment [15]

The objectives of the present research were to evaluate the antiulcer activities of the methanol extract of the leaves of Agelanthus dodoneifolius using various animal models. Therefore, the present study was undertaken for the purpose of verifying its use by the locals in the treatment of ulcer.

\section{Material and methods}

The present work was designed to determine the anti-ulcer activities of the medicinal plant Agelanthus dodoneifolius. This was performed at the Department of Biochemistry, Federal University of Technology, Minna, Nigeria. In order to ascertain the anti-ulcer activities activities of Agelanthus dodoneifolius, the following steps were involved.

\subsection{Plant material collection}

Agelanthus dodeneifolius leaves were collected around March, 2018, from Busu of Lavun Local Government Area (9027'N 5038'E) in Niger state and were identified in the Department of Plant Biology, Federal University of Technology Minna, Niger State. Plant selection was as a result of ethnobotanical study of the medicinal plant used traditionally on the treatment of ulcer in Nupe Kingdom, North Central Nigeria.

\subsection{Animals}

Wistar rats of about $180 \pm 2 \mathrm{~g}$ weights were obtained, and are in the range of 6 weeks old from Animal House of the Federal University of Technology Minna were used for the experiments. The animals were conveniently housed under standard environmental conditions Temperature $(27 \pm 2)^{\circ} \mathrm{C} ; 70 \%$ relative humidity; $12 \mathrm{~h}$ daylight/night cycle) and had free access to commercial feed pellets and water.

\subsection{Fractionation of the extract}

Solubilization of the extract was done in methanol: water in 80:20 and the resulting solution was subjected to successive extractions in separating funnel with the solvents: $n$-hexane, ethyl-acetate (AcOEt) and methanol (MeOH). Three fractions were obtained from the extracts.

\subsection{Antiulcer and Cytoprotective Studies}

Three (3) animals for each group: Oral administration of drugs or saline was achieved at 9:00am daily for 8 days. Treatment was conducted for 8 days, the rats to be experimented were kept fasting for 36 hours in separate cages with raise wide mesh wire bottom to ensure complete emptying of the stomach and to prevent coprophagia (eating their faeces) before subjecting them to ulcerogen, and allowed water ad-libitum

Group 1: Vehicle (Distilled water) Control

Group 2: Distilled water + Aspirin+ Cemetidine (50 mg/kg bw)

Group 3: Distilled water + Aspirin + Crude extract $(800 \mathrm{mg} / \mathrm{kg} \mathrm{bw})$

Group 4: Distilled water + Aspirin + Crude extract (1600 mg/kg bw) 
Group 5: Distilled water + Aspirin+ Methanolic fractions $(800 \mathrm{mg} / \mathrm{kg} \mathrm{bw})$

Group 6: Distilled water + Aspirin + Ethylacetate fractions $(800 \mathrm{mg} / \mathrm{kg} \mathrm{bw})$

Group 7: Distilled water + Aspirin+ n-hexane fractions $(800 \mathrm{mg} / \mathrm{kg} \mathrm{bw})$

Same design was used for ethanol model using ethanol.

\subsection{Ethanol (EtOH) and aspirin (ASP) ulcer induction}

The Ethanol induced ulcer was carried in rats by administering Ethanol as described by Hollander et al. [16] and Aspirin Induced ulcer was carried out as described by Rajkapoor et al. [17].

\subsection{Induced ulcers}

Aspirin was administered orally on the day of experiment at about $10 \mathrm{AM}$ with the help of an orogastric tube in the form of an aqueous water suspension ( $200 \mathrm{mg} / \mathrm{kg}$, per oral) and animals were sacrificed after 4 hours of administration. The stomach was incised along with the greater curvature and examined for ulcers as described earlier.

\subsection{Biochemical parameters}

A 50 dilution of the stomach homogenate was prepared and the activities of superoxide dismutase and catalase were evaluated as described by Ekanem \& Yusuf, [18]. The levels of Malonaldehyde as an index of lipid peroxidation was estimated as described previously [19] while method described by [20] was used for total proteins estimation. Histological examination was conducted following the procedure of [21].

\subsection{Statistical analysis}

Data obtained in this study were analysed using the statistical software SPSS 16.0, 2016. Numerical data were presented as Mean \pm SD. The significance of the mean difference between two independent groups was determined using Student's t-test and one-way analysis of variance (ANOVA) while multiple comparisons were used when comparing more than two groups. A p-value $<0.05$ was considered significant.

\section{Results and discussion}

The methanol fraction had the highest ulcer protective effect $(73.33 \pm 7.40 \%)$, better than the cimetidine $(60.00 \pm 8.54$ $\%)$ while the ethyl acetate fraction had the least $(26.66 \pm 6.66 \%)$ in ethanol model, however, in acetylsalicylate model, crude extract exhibited the highest $(54.16 \pm 4.16 \%)$ and the lowest $(33.33 \pm 4.16 \%)$ protective effect at 1600 and 800 $\mathrm{mg} / \mathrm{kg}$ bw respectively. The methanol faction preserved the integrity of the epithelial mucosal better than the other fractions. Treatment with crude and fractions of $A$. dodenofolius significantly $(\mathrm{p}<0.05)$ increased the activities of SOD and Catalase and decreases the MDA concentration when compared with ulcerative untreated rats in both ulcer models.

Methanol crude extracts and fractions of A. dodoneifolius significantly $(\mathrm{p}<0.05)$ decrease the Malonaldehyde (MDA) content, compare to the control group of both models. An increase in MDA content is correlated to an increase in tissue damage. The control group of both the acetylsalicylate model and the ethanol model were elevated compared to the treated groups which had significantly $(\mathrm{p}<0.05)$ reduced MDA content. The MDA is the functional product of lipid peroxidation and it is used to determine lipid peroxidation levels [22]. Increasing lipid peroxidation production is an important cause of NSAID's damaging effects on stomach tissue [22]. Earlier studies have shown that gastric damage caused an increased MDA level [23]

The result indicates marked increase in the catalase level when administered with methanol crude extract and fractions for the two models (ethanol and acetylsalicylate) as compared to the control. Catalase involvement in gastric injury caused by ethanol is seen when catalase functions in the conversion of hydrogen peroxide to water. Catalase activity is indicative of oxidative stress and significantly $(\mathrm{p}<0.05)$ increased upon induction by the ethanol and acetylsalicylate models [24]. These findings were in accordance with the main experimental studies which showed that catalase activity in stomach tissue increased gastric damage [25]

In intact rat stomach tissue superoxide dismutase (SOD) activity was significantly $(\mathrm{p}<0.05)$ lower than that of the control rats in the ethanol model and there were no significant $(p<0.05)$ difference in SOD content of the acetylsalicylate model. SOD activity is least in damage tissues and it is highest in healthy tissues [26] 
The results revealed that the mean ulcer score of the two models (acetylsalicylate and ethanol) in the untreated groups were $8.00 \pm 0.52$ and $5.00 \pm 0.57$ respectively. The mean ulcer scores indicated the severity of the ulcer induction and the acetylsalicylate has more ulceration as compared with the ethanol model. . The higher mean ulcer score of the acetylsalicylate indicated higher epithelial damage than the ethanol model during ulceration and this findings can be compared to the earlier studies [27]. The methanol fraction had the highest ulcer protective effect $(73.33 \pm 7.40 \%)$, better than the cimetidine $(60.00 \pm 8.54 \%)$ while the ethyl acetate fraction had the least $(26.66 \pm 6.66 \%)$ in ethanol model, however, in acetylsalicylate model, crude extract exhibited the highest (54.16 $\pm 4.16 \%)$ and the lowest $(33.33 \pm 4.16 \%)$ protective effect at 1600 and $800 \mathrm{mg} / \mathrm{kg}$ bw respectively.

The histological findings revealed that the methanol faction preserved the integrity of the epithelial mucosal better than the other fractions. The result may not be unconnected with the earlier report of the acetylsalicylate damaging more epithelium, hence low level of protection as compared to the ethanol model in this study. The negative control without treatment shows discontinuity in mucosal epithelium in acetylsalicylate model of rat ulceration. A standard drug (cimetidine) of $50 \mathrm{~g} / \mathrm{kg}$ bw showed no ulcer formation and a similar result was gotten from the treated group when a crude extract of $A$. dodoneifolius with a dose of $1600 \mathrm{mg} / \mathrm{kg}$ bw was administered.

Table 1 Effects of crude extracts and fractions on ulceration in rats

\begin{tabular}{|c|c|c|c|c|c|}
\hline & \multirow[b]{2}{*}{$\begin{array}{l}\text { Conc. } \\
\text { (mg/kg bw) }\end{array}$} & \multicolumn{2}{|c|}{ Ethanol Model } & \multicolumn{2}{|c|}{ Acetylsalicylate model } \\
\hline & & $\begin{array}{l}\text { Mean } \\
\text { Ulcer }\end{array}$ & $\begin{array}{l}\text { Protective } \\
\text { index }(\%)\end{array}$ & $\begin{array}{l}\text { Mean } \\
\text { Ulcer }\end{array}$ & $\begin{array}{l}\text { Protective } \\
\text { index }(\%)\end{array}$ \\
\hline Crude extract & 800 & $3.33 \pm 0.33 b$ & $33.33 \pm 6.66^{a}$ & $5.33 \pm 0.33^{c}$ & $33.33 \pm 4.16^{a}$ \\
\hline Crude extract & 1600 & $2.00 \pm 0.57$ a & $60.00 \pm 9.54 \mathrm{bc}$ & $3.66 \pm 0.33 \mathrm{ab}$ & $54.16 \pm 4.16^{b}$ \\
\hline Standard drug & 50 & $2.00 \pm 0.57 \mathrm{a}$ & $60.00 \pm 8.54 \mathrm{bc}$ & $2.00 \pm 0.57^{a}$ & $73.33 \pm 7.40$ \\
\hline Control & - & $5.00 \pm 0.57 \mathrm{c}$ & - & $8.00 \pm 0.57 \mathrm{~d}$ & - \\
\hline Methanol fraction & 800 & $2.00 \pm 0.57$ a & $73.33 \pm 6.66^{c}$ & $3.33 \pm 0.88^{b}$ & $50.00 \pm 7.21$ \\
\hline Ethyl-acetate fraction & 800 & $3.33 \pm 0.33^{b}$ & $26.66 \pm 6.66^{b}$ & $4.33 \pm 0.33 b c$ & $45.83 \pm 4.16^{a}$ \\
\hline Hexane fraction & 800 & $2.33 \pm 0.33^{a}$ & $53.33 \pm 6.66^{b c}$ & $5.00 \pm 0.57 b c$ & $45.83 \pm 8.02^{a}$ \\
\hline
\end{tabular}

Values are means \pm SEM of triplicate determination. Mean values with the different superscript on the same column are significantly $(p<0.05)$ different from each other

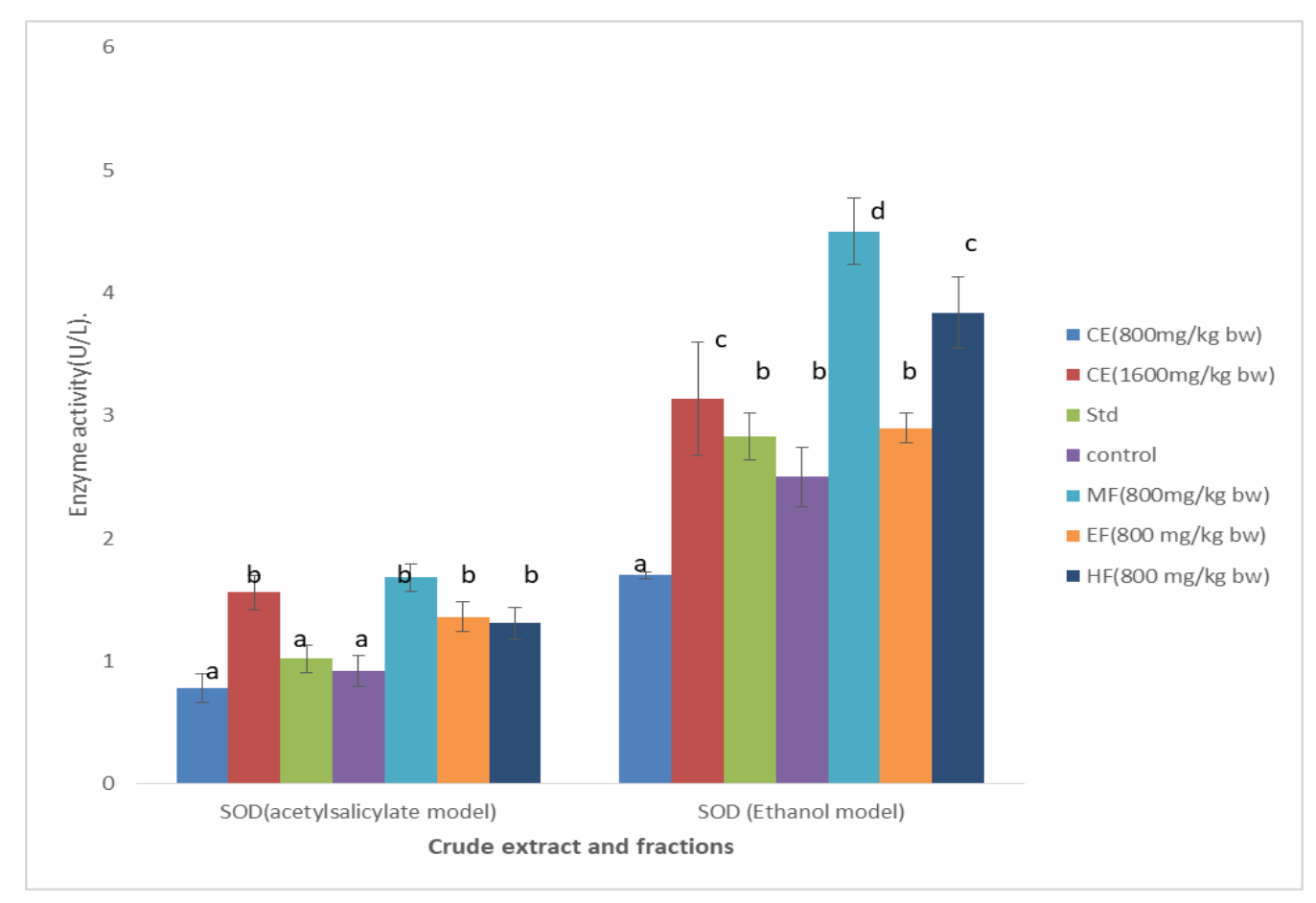

Figure 1 Effects of crude A. dodoneifolius extract and fractions on serum Superoxide dismutase in ulcerated rats 
Mohammed et al. / GSC Biological and Pharmaceutical Sciences 2019, 09(01), 053-061

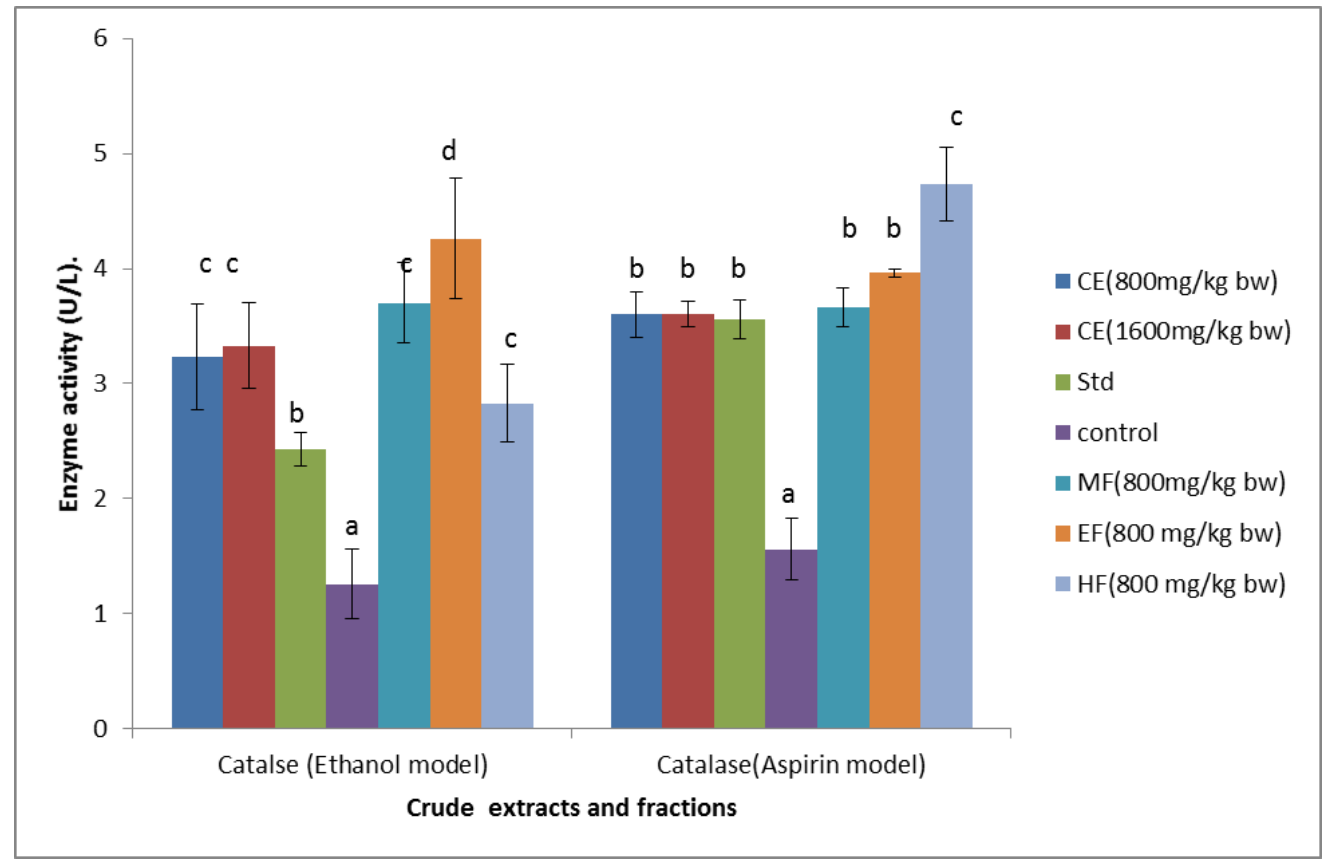

Figure 2 Effects of crude $A$. dodoneifolius extract and fractions on serum Catalase in ulcerated rats

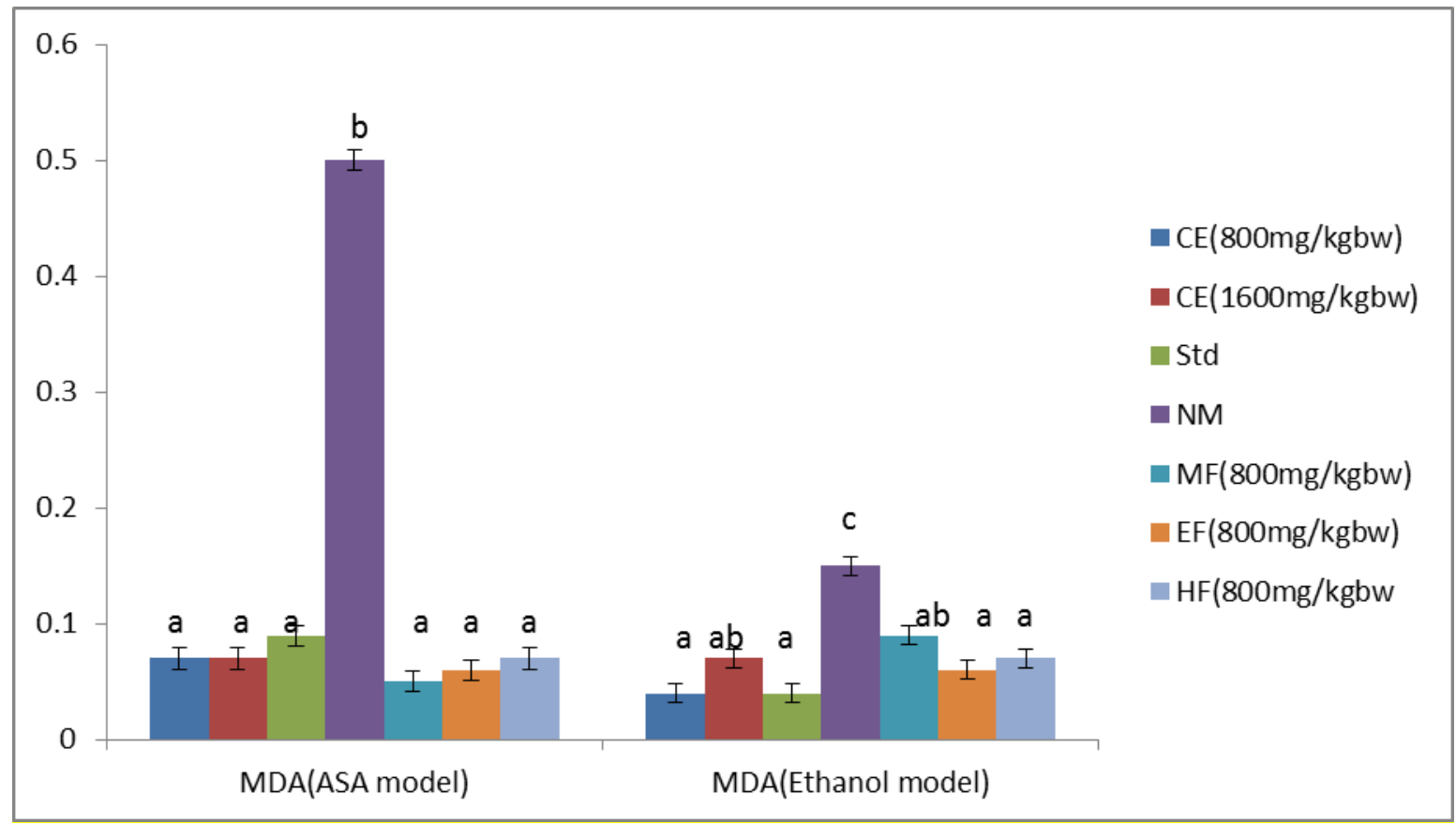

Figure 3 Effects of crude A. dodoneifolius extract and the fractions on the serum Malonaldehyde ulcerated rats 


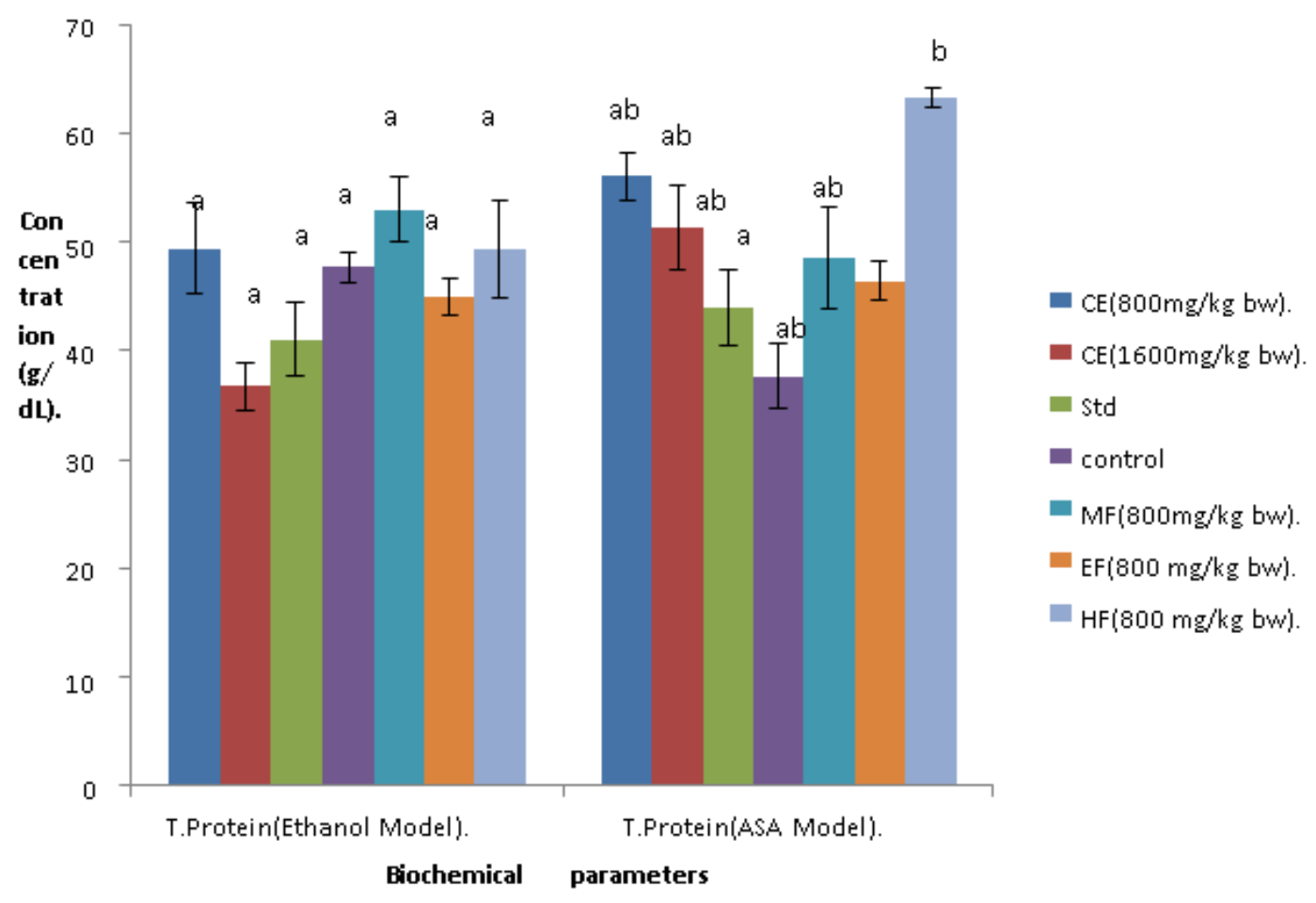

Figure 4 Effects of crude A. dodoneifolius extracts and fractions on serum total protein in ulcerated rats
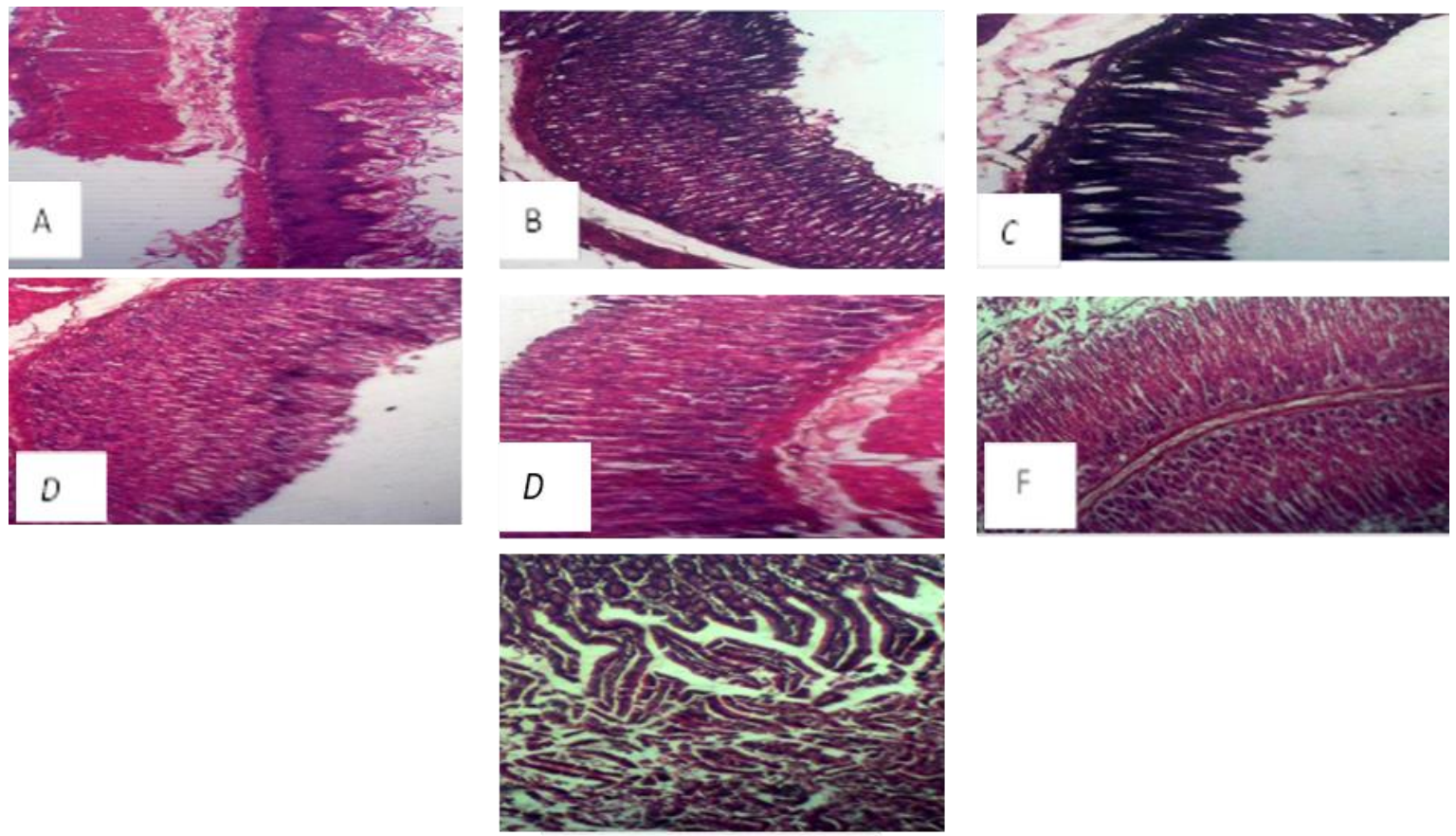

Figure 5 Cross section of acetylsalicylate ulcer induced rat stomach mucosa section x 400

A= Negative Group showing discontinuity in mucosal epithelium, B: Standard group showing normal mucosal epithelium with no ulcer, C: Treated with crude extract at $800 \mathrm{mg} / \mathrm{kg}$ bw showing Epithelium with edematous submucosa, D; Treated with crude extract at $1600 \mathrm{mg} / \mathrm{kg}$ bw showing no ulcer formation, E; treated with $800 \mathrm{mg} / \mathrm{kg}$ bw methanol fraction (showing discontinuity in normal epithelium), F: treated with $800 \mathrm{mg} / \mathrm{kg}$ bw ethyl acetate fraction 
(showing Hemorrhage and discontinuity in the lining epithelium), G: treated with $800 \mathrm{mg} / \mathrm{kg}$ bw hexane fraction (showing Discontinuity in the lining epithelium and hyperplastic mucosa)
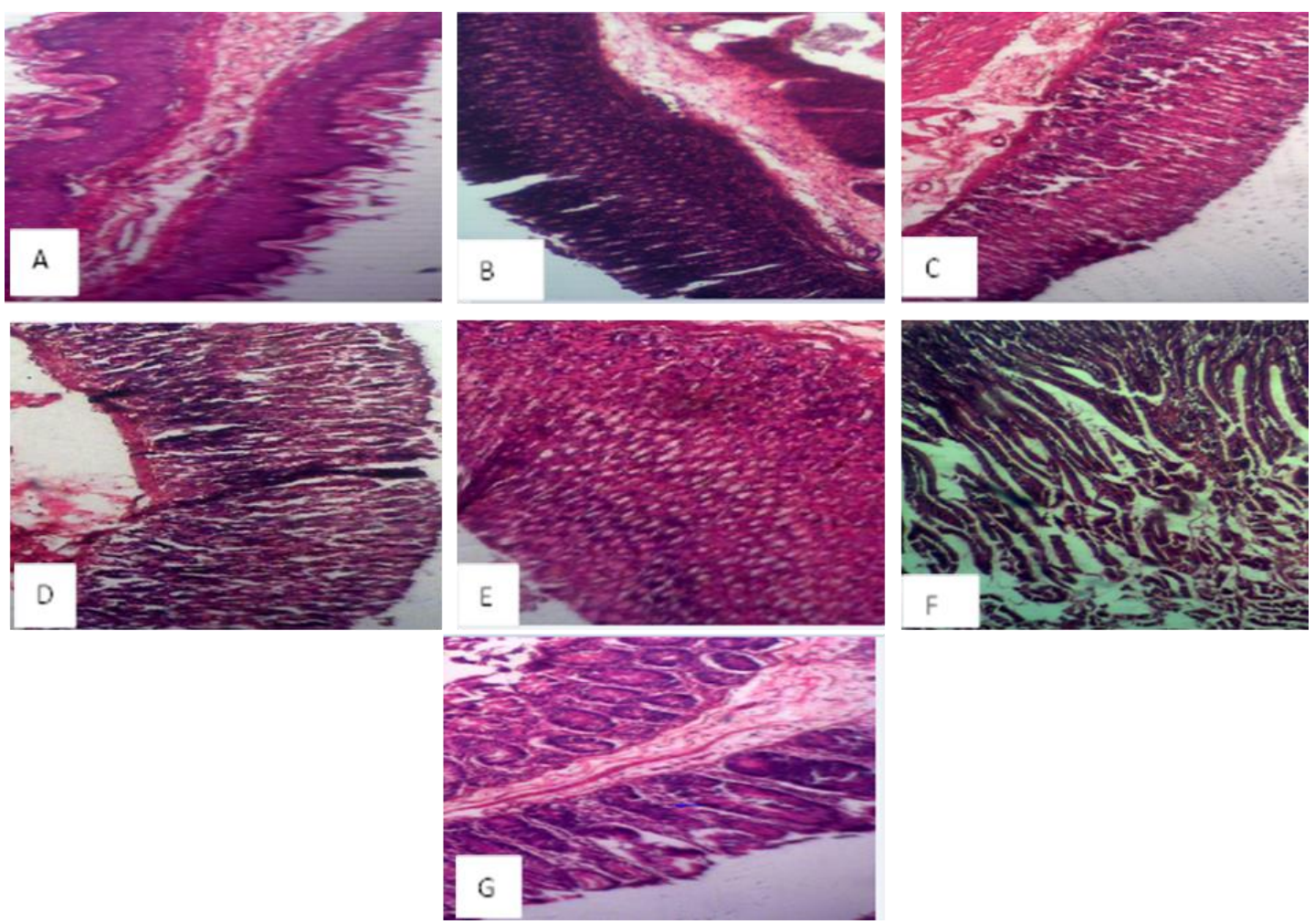

Figure 6 Cross section of ethanol ulcer induced rat stomach mucosa section $\mathrm{x} 400$

A= Negative Group showing discontinuity in mucosal epithelium, B: Standard group showing nucosal epithelium with no ulcer, C: Treated with crude extract at $800 \mathrm{mg} / \mathrm{kg}$ bw showing hemorrhage and discontinuity in mucosal epithelium, D; Treated with crude extract at $1600 \mathrm{mg} / \mathrm{kg}$ bw showing Mild hyperplastic mucosa, E; treated with $800 \mathrm{mg} / \mathrm{kg}$ bw methanol fraction (showing no ulcer formation), F: treated with $800 \mathrm{mg} / \mathrm{kg}$ bw ethyl acetate fraction (showing discontinuity in the lining epithelium and hyperplastic mucosa), G: treated with $800 \mathrm{mg} / \mathrm{kg}$ bw hexane fraction (showing Epithelium with small atrophic glands, thick muscularis, and inflammatory infiltrate)

\section{Conclusion}

The study showed that the crude extract and fractions (methanol, n-haxane and ethylacetate) of Agelanthus dodoneifolius have significant anti-ulcer activity with high safety margin. The crude methanolic extract of the leaves and its various fractions possess significant phytochemicals and antioxidant activities demonstrates potent anti-ulcer activities on the Wister rats. The evidence obtained supported the use of the plant for treatment of ailment as traditional herb by the natives, particularly Africans. Therefore, the crude extract and fractions of Agelanthus dodoneifolius are potential sources of new plant based antiulcer agent.

\section{Compliance with ethical standards}

\section{Acknowledgments}

The authors are thankful to the Department of Biochemistry, Federal University of Technology Minna, for the laboratory space and also acknowledge the expertise of the Laboratory Technologists during the bench work.

\section{Disclosure of conflict of interest}

The authors declare that they have no competing interests. 


\section{Statement of ethical approval}

The principles governing the use of laboratory animals as laid out by the Federal University of Technology, Minna Committee on Ethics for Medical and Scientific Research and also existing internationally accepted principles for laboratory animal use and care as contained in the Canadian Council on Animal Care Guidelines and Protocol Review were duly observed.

\section{References}

[1] Cadirci E, Suleyman H and Aksoy H. (2007). Effects of onosma armeniacum root extract on ethanol-induced oxidative stress in stomach tissue of rats Journal of Chemistry and boilogical interaction, 170, 40-8.

[2] Brucker MC and Faucher MA. (1997). Pharmacologic management of common gastrointestinal health problems in women Journal of Nurse-Midwifery 42, 145- 162.

[3] Wallace JL, McKnight W, Reuter BK and Vergnolle N. (2000). NSAID-induced gastric damage in rats: requirement for inhibition of both cyclooxygenase 1 and 2 Gastroenterology, 119. (3), 706-714.

[4] HoogerwerfWA, Pasricha PJ, Hardman JG, Limbird LE and Goodman GA. (2001). Agents used for control of gastric acidity and treatment of peptic ulcers and gastroesophageal reflux disease, in The Pharmacological Basis of Therapeutics McGraw-Hill, New York, NY, USA, 10th edition, 1005-1019.

[5] Abdelwahab SI, Taha ME, Abdulla MA, Nordin N and Hadi AHA. (2013). Gastroprotective mechanism of Bauhinia thonningii Schum Journal of Ethnopharmacology 148, 277-286.

[6] Oh TY, Ahn GJ, Choi SM, Ahn BO and Kim WB. (2005). Increased susceptibility of ethanol-treated gastric mucosa to naproxen and its inhibition by DA-9601, an Artemisia asiatica extract World Journal of Gastroenterology, 11, $7450-7456$.

[7] La Casa C, Villegas I, Alarcon de La, Lastra C, Motilva V and Calero M. (2000). Evidence for protective and antioxidant properties of rutin, a natural flavone, against ethanol induced gastric lesions Journal of Ethnopharmacology, 71, 45-53.

[8] Rios ERV, Rocha NFM, Venâncio ET, Moura BA and Feitosa, ML. (2010). Mechanisms involved in the gastroprotective activity of esculin on acute gastric lesions in mice Chemico-Biological Interactions, 188, 246254.

[9] Efuntoye MO, Ayodele AE, Thomas BT and Ajayi TO. (2010). Does host plant affect the antibacterial activity of Tapinanthus bangwensis. (Engl and K Krause) Danser. (Loranthaceae)? Journal of Medicinal Plants Research, $4(13), 1281-1284$.

[10] Wang H, Naghavi M, Allen C and Foreman K. (2016). Global regional and national life expectancy all-cause mortality, and cause specific mortality for 249 causes of death, 1980-2015: a systematic analysis for the Global Burden of Disease Study Lancet, 388. (10053), 1459-1544.

[11] Malfertheiner P, Megraud F and O'Morain CA. (2012). European Helicobacter Study Group Management of Helicobacter pylori infection the Maastricht IV/ Florence Consensus Report Gut, 61. (5), 646-664.

[12] Recknagel RO. (1983). A new direction in the study of carbon tetrachloride hepatotoxicity Opinion in Gastroenterology, 25(6), 537-543.

[13] Roy H. (1994) Free radical damage and its control Elsevier science, 125-134.

[14] Brewer MS. (2011). "Natural antioxidants: sources, compounds, mechanisms of action, and potential applications," Comprehensive Reviews in Food Science and Food Safety, 10(4), 221-247.

[15] Dhikav V, Singh Pande S, Chawla A and Anand KS. (2003). Non-steroidal drug-induced gastrointestinal toxicity: mechanisms and management. Indian Academy of Clinical Medecine, 4. (4), 315-322.

[16] Hollander D, Tarnawski A, Krause WJ and Gergely H. (1985). Protective effect of sucralfate against alcoholinduced gastric mucosal injury in the rat Macroscopic, histologic, ultrastructural, and functional time sequence analysis," Journal of Gastroenterology, 88(1), 366-374.

[17] Rajkapoor BR, Anandnan B and Jayakar B. (2002). Antiulcer effects of Nigelle sativa linn against gastric ulcer in rats, Current Sciences, 82, 177-179. 
[18] Ekanem JT and Yusuf OK. (2005). Activities of alkaline phosphatase, glutamate oxaloacetate transaminase and glutamate pyruvate transaminase in liver and serum of Trypanosoma brucei-infected rats treated with honey, Biokemistri, 17,185-19.

[19] Draper HH and Hadley M. (1990). Malondialdehyde determination as index of lipid peroxidation Methods Enzymol, 186, 421-31.

[20] Gornal AG, Bardwil GS and Divid MM. (1946). Determination of serum proteins by means of Biuret reactions Journal of Biology and Chemistry, 77, 751-766.

[21] Raju D, Chitra V and Ashish K. (2009). Evaluation of anti-ulcer activity of methanolic extract of Terminalia chebula fruits in experimental rats Journal of Pharmaceutical Sciences, 1, 101.

[22] Neilsen F, Mikkelsen BB and Andersen HR. (1997). Plasma malondialdehyde as biomarker for oxidative stress Journal of Clinical Chemistry, 43, 1209-14.

[23] Kuntepe Y, Borikei B, Karaca M and Salman S. (2009). Effect of acute and chronic administration of progesterone, estrogen, FSH and LH on oxidant and antioxidant parameters in rat gastric tissues Chemistry of Biological Interaction, 182, 1-6.

[24] Sen S, Asokkumer K and Subhadradevi, V. (2013). Antiulcerogenic Effect of Galic Acid Indian Journal of Pharmaceutical Science, 75. (2), 149-155.

[25] Demircan BY, Celik G and Suleyman H. (2005). Effects of indomethacin, celecoxib and melaxican on gluthathione, Malondialdehyde and myloperioxidase in rat gastric tissue Journal of Ethnopharmacology, 17, 383-388.

[26] Halliwell B. (1974) Free radical antioxidant and human diseases: curiosity; cause or consequence? Lancet, 34, 721-4.

[27] El-missiry, EA, El-sayed IH and Othman AI. (2001). Protection by mental complexes with SOD activity against oxidative gastric injury induced by indomethacin and ethanol in rats Analytical Clinical Biochemistry, 38, 694700 .

\section{How to cite this article}

Mohammed BA, Jigam AA, Abubakar A, Abdulkadir A and Audu M. (2019) Antiulcerogenic activities of Agelanthus dodoneifolius leaf against acetyl-salicylate and ethanol-induced ulceration in rats. GSC Biological and Pharmaceutical Sciences, 9(1), 53-61. 